\title{
A novel prothrombotic pathway in systemic sclerosis patients: possible role of bisphosphonate-activated
} $\gamma \delta$ T cells

\section{Victoria Marcu-Malina ${ }^{1}$, Alexandra Balbir-Gurman ${ }^{2}$, Rima Dardik ${ }^{3}$, Yolanda Braun-Moscovici ${ }^{2}$, Michael J. Segel ${ }^{4}$ and Ilan Bank ${ }^{1,5,6 *}$}

\author{
1 Laboratory of Immunoregulation, Sheba Medical Center, Ramat Gan, Israel \\ 2 B Shine Rheumatology Unit, Rambam Health Care Campus, Rambam Medical Center, Haifa, Israel \\ ${ }^{3}$ Institutes of Thrombosis and Hemostasis, Sheba Medical Center, Ramat Gan, Israel \\ ${ }^{4}$ Institute of Pulmonary Diseases, Sheba Medical Center, Ramat Gan, Israel \\ ${ }^{5}$ Department of Medicine F, Sheba Medical Center, Ramat Gan, Israel \\ ${ }^{6}$ Department of Medicine, Sackler School of Medicine, Tel Aviv University, Tel Aviv, Israel
}

\section{Edited by:}

Dieter Kabelitz, Christian-Albrechts

University of Kiel, Germany

Reviewed by:

John J. Miles, QIMR Berghofer

Medical Research Institute, Australia

Paul Fisch, University Medical Center

Freiburg, Germany

\section{${ }^{*}$ Correspondence:}

Ilan Bank, Department of Medicine F, Sheba Medical Center, Tel Hashomer 52621, Israel

e-mail: ibank@post.tau.ac.il
Objectives: Infusions of aminobisphonates (ABP) activate $\mathrm{V} \gamma 9 \delta 2 \mathrm{~T}$ cells in vivo and induce an acute inflammatory response in $30 \%$ of patients treated for osteoporosis. Following the observation of digital thrombosis in a systemic sclerosis (SSc) patient after treatment with an intravenous $\mathrm{ABP}$, zoledronate (Zol), we evaluated whether patient and control peripheral blood (PB) mononuclear cell (MC, PBMC) acquire a prothrombotic phenotype in response to Zol.

Results: $\mathrm{V} \gamma 982 \mathrm{~T}$ cells of both patients and healthy donors (HD) upregulated the CD69 activation antigen and secreted tumor necrosis factor (TNF) $\alpha$ in response to Zol in vitro. In addition, exposure to either Zol or lipopolysaccharide (LPS), or to both additively, induced expression of the highly procoagulant, tissue factor (TF)-1 on CD14+ monocytes. Importantly, only Zol-induced TF-1 was blocked by a monoclonal antibody to TNF $\alpha$. Interestingly, we found that SSc, but not HD, V $\delta 1+T$ cells were concurrently activated by Zol to produce interleukin (IL)-4. Addition of plasma from the blood of the SSc patient who developed critical digital ischemia after infusion of Zol, but neither plasma from a second patient with no adverse clinical response to Zol infusion nor of a HD, strongly enhanced Zol-induced monocyte TF-1, which could still be blocked by anti-TNF $\alpha$.

Conclusion: Aminobisphonates induced secretion of TNF $\alpha$ by $\vee \gamma 9 \delta 2+T$ cells may lead to TNF $\alpha$-dependent induction of procoagulant TF-1 induction on monocytes. In certain clinical settings, e.g., SSc, TF-1+ monocytes could play a role in triggering clinically relevant thrombosis.

Keywords: $\mathrm{T}$ cells, $\gamma \delta \mathrm{T}$ cell, scleroderma, tissue factor, thrombosis, aminobisphosphonate, $\mathrm{V} \gamma 9 \delta 2 \mathrm{~T}$ cells

\section{INTRODUCTION}

$\gamma \delta \mathrm{T}$ cells are a subset of $\mathrm{T}$ cells combining innate and adaptive functions (1). In Caucasians, $50 \%$ of the circulating $\gamma \delta \mathrm{T}$ cells express the $\gamma 9$ and $\delta 2$ genes in the Variable $(\mathrm{V})$ region of the $\gamma \delta \mathrm{T}$ cell receptor (TCR) $\mathrm{V} \gamma 9 \delta 2 \mathrm{~T}$ cells (2). V $\gamma 9 \delta 2 \mathrm{TCR}$ recognize metabolites produced in the classical (isopentenyl pyrophosphate, IPP) and alternative [(E)-4-hydroxy-3-methyl-but-2-enyl pyrophosphate (HMBPP)] mevalonate metabolic pathways. These antigens are presented for TCR-mediated recognition by CD277, a ubiquitously expressed cell surface membrane antigen presenting molecule (APM) (3). Together with co-stimulatory signals delivered by antigen presenting cells (APC), $\mathrm{V} \gamma 982 \mathrm{TCR}-$ CD277/IPP cognitive interactions activate the $\mathrm{V} \gamma 9 \delta 2 \mathrm{~T}$ cells to secrete cytokines and exert cytotoxic effects. A second major subset of $\gamma \delta \mathrm{T}$ cells expresses the V $\delta 1$ gene in the TCR structure, among which a major portion recognize phospholipid antigens (e.g., sulfatide) presented by CD1 family molecules (4).

$\mathrm{V} \delta 1 \gamma \delta \mathrm{T}$ cells have been shown to expand oligoclonally in the PB of certain systemic sclerosis (SSc) patients, infiltrate the skin in early phases of the disease, and may secrete factors enhancing collagen production (5). $\mathrm{V} \gamma 9 \delta 2 \mathrm{~T}$ cells are also functional in SSc patients, since their circulating $\mathrm{V} \gamma 9 \delta 2 \mathrm{~T}$ cells secrete tumor necrosis factor (TNF) $\alpha$ and IFN $\gamma$ and induce fibroblast apoptosis in the presence of exogenously added IPP (6). However, the immunopathogenic significance of these cells concerning the clinical manifestations in SSc patients remains largely unknown.

In this regard, interactions of $\gamma \delta \mathrm{T}$ cells with bisphosphonateactivated CD14+ monocytes may play a critical role. Bisphosphonates block farnesylpyrophosphate synthase (FPPS) downstream 
of IPP in the mevalonate pathway in circulating CD14+ monocytes, increasing intracellular IPP, which is presented to circulating $\mathrm{V} \gamma 9 \delta 2 \mathrm{~T}$ cells leading to their activation $(7,8)$. As a consequence, these cells produce TNF $\alpha$ and IFN $\gamma$, the central mediators of the acute phase response (APR) following infusion of zoledronate (Zol) to patients (8). Accordingly, upon administration of a bisphosphonate drug for osteoporosis or to decrease bone metastasis in cancer, an APR characterized by fever, chills, and arthralgia occurs in up to $30 \%$ of patients (8). Zol also activates dendritic cells and natural killer $(\mathrm{NK})$ cells at least in part dependent upon $\mathrm{V} \gamma 9 \delta 2 \mathrm{~T}$ cell activation $(9,10)$. CD86 and other stimulatory molecules, which enhance activation of other $\mathrm{T}$ cell subsets are also upregulated by Zol on dendritic cells (11). Recently, Zol was also shown to stimulate B cells directly (12). Our recent observation of the rapid onset of gangrene of fingers and toes in a patient with SSc after Zol administration prompted the experiments in this study that were designed to evaluate how bisphosphonate-activated $\gamma \delta$ $\mathrm{T}$ cells could play a pathogenic role in SSc.

\section{MATERIALS AND METHODS \\ PATIENTS}

The study was approved by the Institutional Review Board (Helsinki Committee) of the Sheba Medical Center, Ramat Gan, Israel. All patients participating in the study were seen in the Rheumatology and Pulmonary clinics at Sheba or Rambam medical centers. Patients fulfilled the criteria of the American College of Rheumatology for systemic sclerosis (SSc), also named herein scleroderma (SCL) (13). Controls included six healthy donors (HD), two patients with idiopathic pulmonary fibrosis (IPF), and one patient with polymyalgia rheumatica (PMR).

\section{ISOLATION OF PBMC AND CHARACTERIZATION OF CELL SUBSETS}

PBMC were isolated by Lymphoprep (AXIS-SHIELD, Oslo, Norway) density centrifugation and cultured in growth medium as previously described (14). Cells were stained with fluorochrome conjugated monoclonal antibodies (mAb) specific to CD4, CD3, CD142, CD14, CD69, or isotype control (BD Biosciences), or to human $\mathrm{V} \gamma 9$, V $\delta 2$ (Immunotech), and V $\delta 1$ (Endogen, Pierce) and analyzed by flow cytometry (Calibur, Beckton Dickinson, CA, USA).

\section{TISSUE FACTOR INDUCTION AND INHIBITION}

PBMC were incubated and stimulated either with $2 \mu \mathrm{M}$ of Zol (Novartis) overnight $(\mathrm{ON})$ or with $50 \mathrm{ng} / \mathrm{ml}$ of $E$. coli 0111:B4 lipopolysaccharide (LPS) (InvivoGen) for $3 \mathrm{~h}$. For double LPS + Zol stimulation, cells were cultured with Zol ON then LPS was added for an additional $3 \mathrm{~h}$. Cells were harvested, washed, and stained with CD14 and CD142 specific antibodies. For inhibition experiments, PBMC from HD were cultured in medium with increasing dilutions of either anti-TNF $\alpha$ antibody (Infliximab, Janssen Biologics) or control IgG mix (Gammaplex, Bio Products Laboratory, Herts, UK) prior to stimulation with Zol or/and LPS.

\section{CYTOKINE DETECTION}

Intracellular cytokine detection was performed as previously reported (14). IFN $\gamma$ detection in supernatants was done using the ELISA max Deluxe Sets (Biolegend, CA, USA) according to the manufacturer's instructions.

\section{RESULTS}

\section{SSc-DISEASE SPECIFIC RESPONSE OF V $\boldsymbol{\delta} 1+\mathrm{T}$ CELLS TO ZOL}

Activation of $\gamma \delta \mathrm{T}$ cells in SSc patients was compared to that of healthy individuals and patients with other chronic inflammatory diseases quantitating percentage of cells producing a panel of relevant intracellular cytokines. Thus, PBMC were incubated $\mathrm{ON}$ with Zol and secretion of cytokines was measured by intracellular staining of PB T cell subsets. Percentage of cells among the CD4+, $\mathrm{V} \gamma 9 \delta 2+$, and $\mathrm{V} \delta 1+\mathrm{T}$ cell subsets in PBMC of $3 \mathrm{SSc}$ patients (RP0-2), 3 non-SSc patients with IPF or PMR (Pt 13 ), and $6 \mathrm{HD}$ that were induced to secrete IFN $\gamma$, TNF $\alpha$, IL-4, or IL-9 after $4.5 \mathrm{~h}$ of incubation in medium alone, or with Zol or PMA $(20 \mathrm{ng} / \mathrm{ml})$ and ionomycin $(0.8 \mu \mathrm{M})(\mathrm{P} / \mathrm{I})$ are shown in Figure 1. A significantly higher percentage of IL-4 producing cells was observed among SSc patient's V $\delta 1+$ cells exposed to Zol compared to either non-SSc patients ( $p<0.03$, Student T test) or HD $(p<0.003$, Student T test). In contrast, there was no significant difference in the mean percentage of cells secreting any of the other cytokines in SSc compared to HD in the remaining $\mathrm{T}$ cell subsets. SSc patient IFN $\gamma$ production was, however, significantly lower than in the non-SSc patients among Zol-activated CD4+ $\mathrm{T}$ cells, and $\mathrm{P} / \mathrm{I}$-activated V $\delta 1+\mathrm{T}$ cells. Among SSc V $\delta 1+\mathrm{T}$ cells, the percentage of Zol-activated IL-9 producers were also significantly lower than in non-SSc patients $(p<0.05)$. These results point to a unique pattern of production of cytokines of SSc V $\delta 1+$ $\gamma \delta \mathrm{T}$ cells in response to Zol, relative to HD and patients with other chronic inflammatory and fibrotic diseases, characterized by increased production of IL-4 (relative to both HD and disease controls), and decreased production of IL-9 relative to the disease controls.

\section{ACTIVATION OF PATIENT RP2 $\mathbf{v} \boldsymbol{\gamma} \mathbf{9} \mathbf{2}+\mathbf{T}$ CELLS BY ZOL}

During the course of these studies, only one of our SSc patients (RP2) developed an unusually dramatic APR after receiving intravenous Zol. Since TNF $\alpha$ and IFN $\gamma$ produced by $V \gamma 9 \delta 2 \gamma \delta \mathrm{T}$ cells are thought to be the mediators of the APR and IFN $\gamma$ was weakly produced in SSc patients in response to Zol (Figure 1), we examined in further detail how Zol had affected TNF $\alpha$ production by this patient's (RP2) PB T cell subsets. As expected, CD4+, V $\gamma 9 \delta 2$ as well as $\mathrm{V} \delta 1+\mathrm{T}$ cells in PBMC of RP2, RP1, and a healthy blood donor all increased their intracellular $\mathrm{TNF} \alpha$ in response to $\mathrm{P} / \mathrm{I}$, an activating stimulus for $\mathrm{T}$ cells that bypasses signals dependent upon cognitive TCR-antigen interactions. Zol potently induced $\mathrm{RP} 2 \mathrm{~V} \gamma 9 \delta 2 \mathrm{~T}$ cells (but not CD4+ or $\mathrm{V} \delta 1+\mathrm{T}$ cells) to produce $\mathrm{TNF} \alpha$, similar to its effect on a HD PBMC (Figure 2) whereas those of RP1 an SSc patient who had received Zol but no clinical APR did not secrete TNF $\alpha$ in response to Zol application in vitro. Production of TNF $\alpha$ was linked to Zol-dependent activation of $\mathrm{V} \gamma 9 \delta 2+\gamma \delta \mathrm{T}$ cells. Thus, a markedly increased expression of CD69 on the surface of $\mathrm{V} \gamma 9 \delta 2$ cells (but not $\mathrm{V} \delta 1+$ cells or CD4+ T cells) was concomitantly noted in the presence of Zol on RP2 and HD but not on RP1 V $\gamma 9 \delta 2+\mathrm{T}$ cells. In contrast, P/I stimulation increased CD69 expression in all $\mathrm{T}$ cell subsets in all individuals tested (except in HD V $\delta 1+$ cells). 


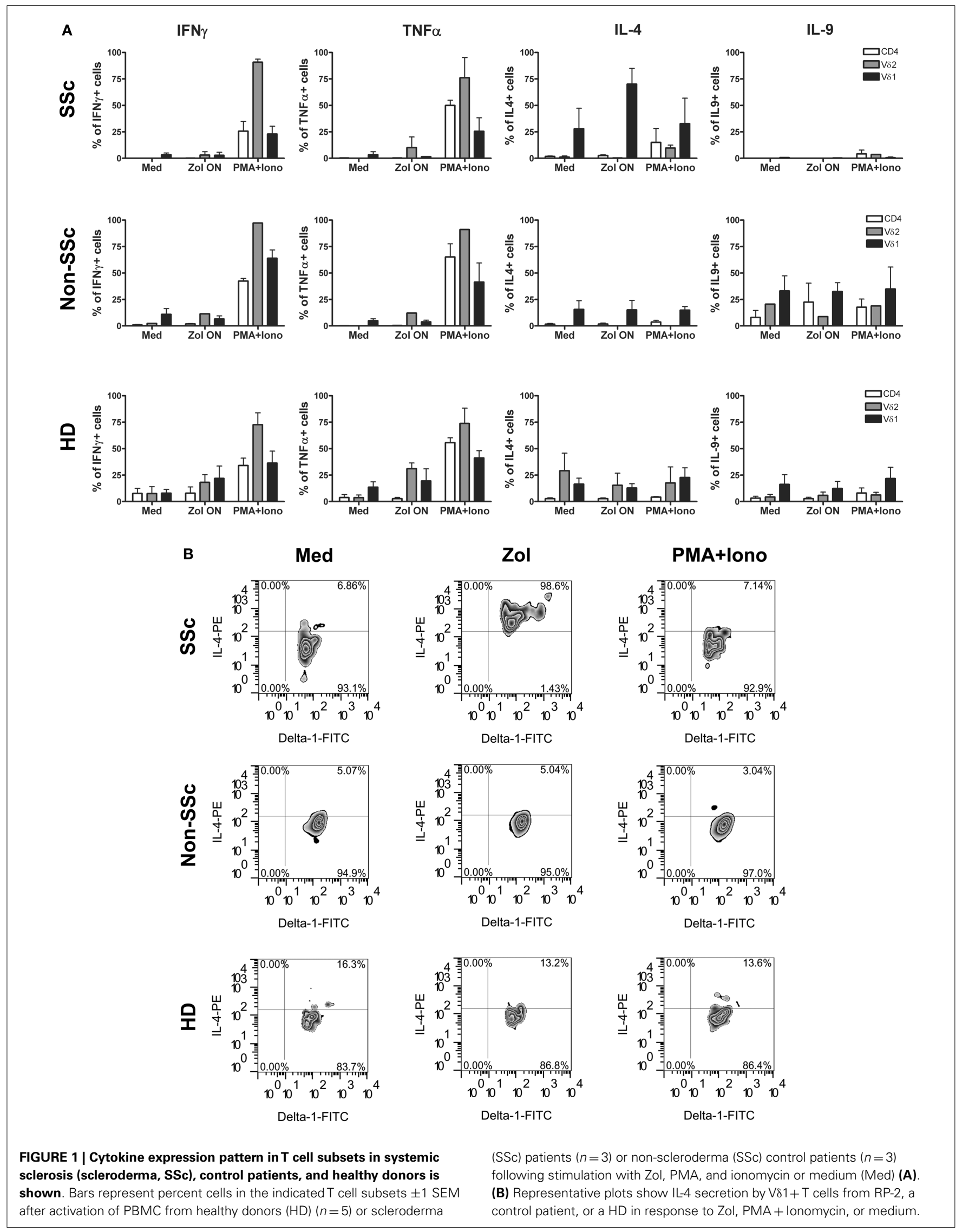




\section{A}

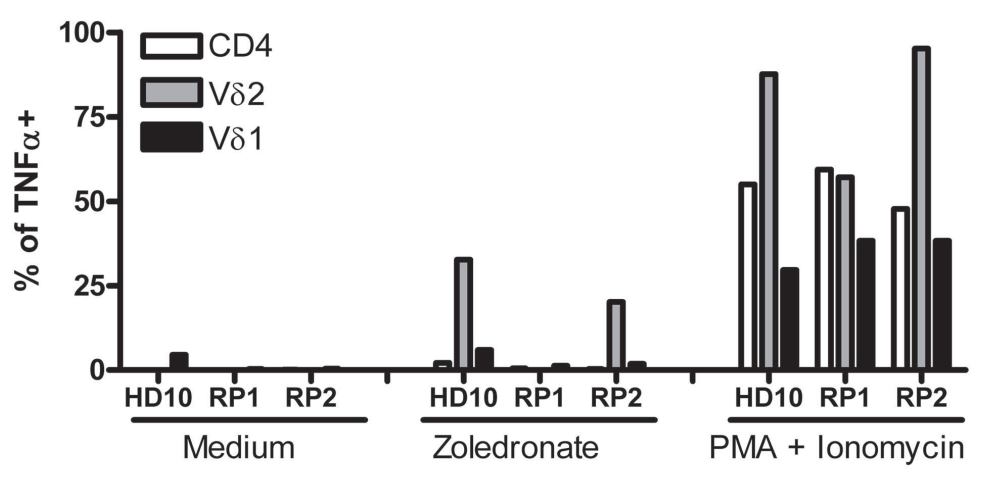

B

CD4

HD10
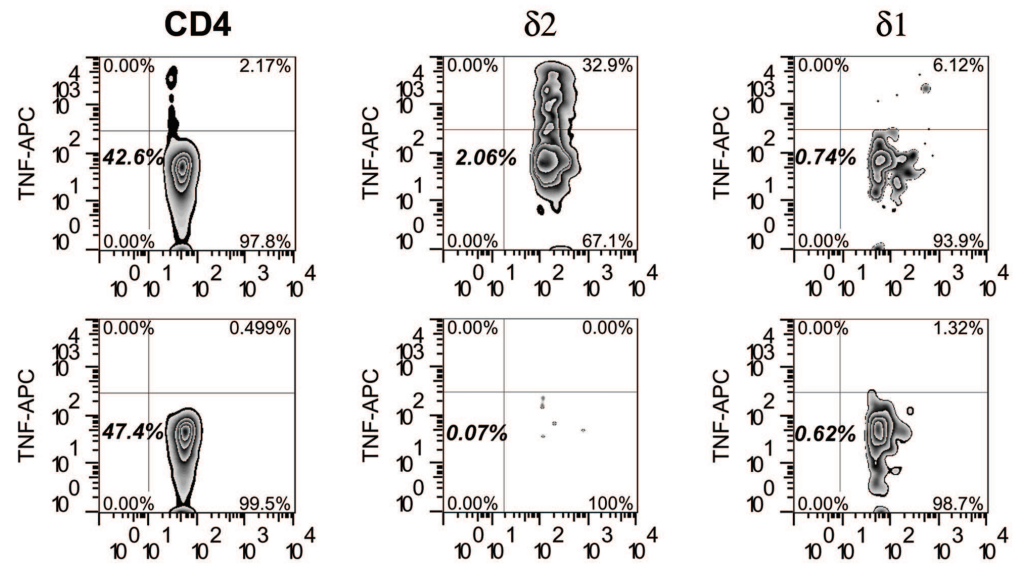

RP1
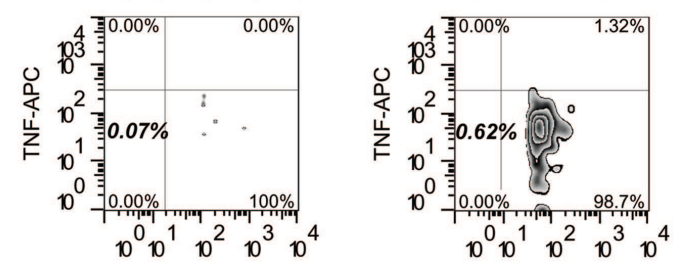

RP2
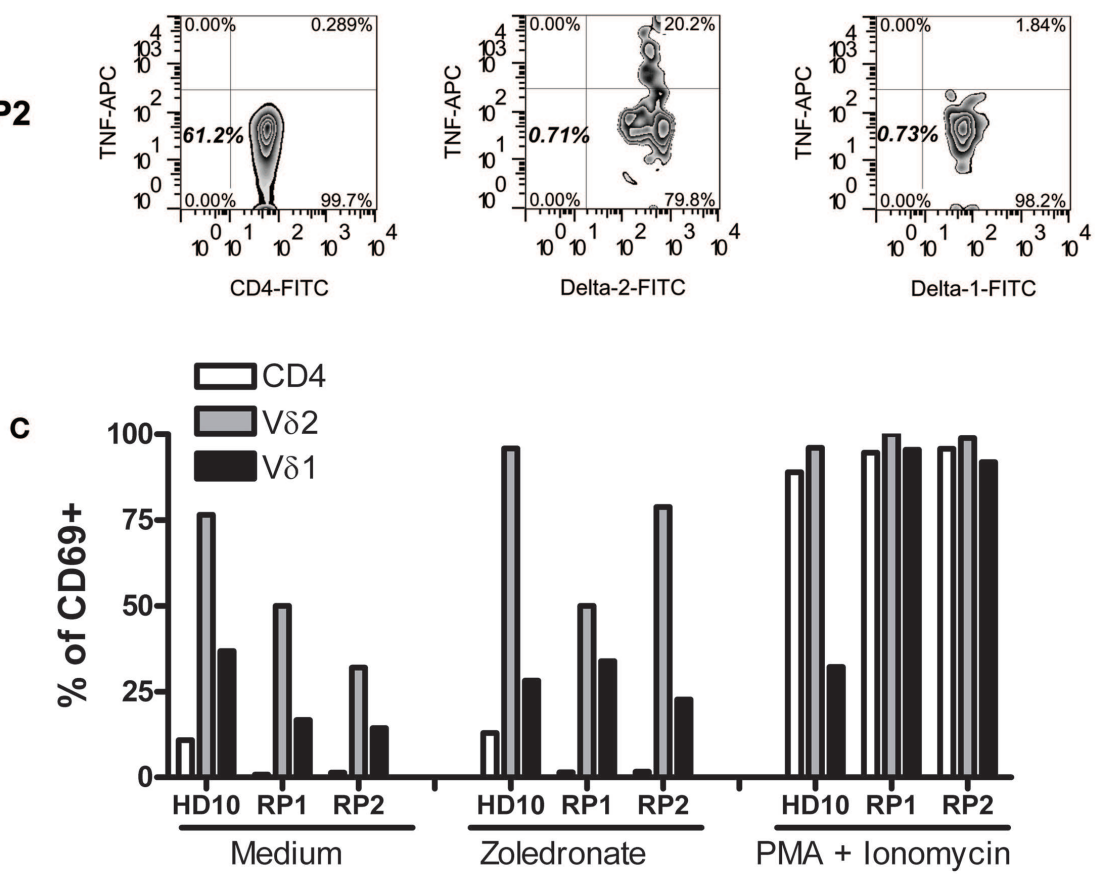

FIGURE $2 \mid \mathrm{V} \gamma \mathbf{9} \mathbf{2} \mathbf{T}$ cells of patient RP2 produced TNF $\alpha$ in response to zoledronate. Bars represent percent cells of HD10, and of SSc patients RP2 and RP1, within the indicated T cells subsets expressing intracellular TNF $\alpha$ (A) or surface CD69 (C) after stimulation with medium, Zol or PMA, and ionomycin. (B) Representative FACS plots of TNF $\alpha$ staining in the corresponding $T$ cells from patients indicated on the left after Zol stimulation. Numbers indicate percentages of the particular cell population in the respective rectangle. 


\section{INDUCTION OF TNF $\alpha$-DEPENDENT TISSUE FACTOR ON CD14+ MONOCYTES BY ZOL}

The occurrence of digital ischemia during the APR in RP2 prompted us to examine whether $\mathrm{TNF} \alpha$ produced by $\mathrm{V} \gamma 9 \delta 2+$ cells in response to $\mathrm{Zol}$ is sufficient to induce tissue factor (TF)1 , a potent procoagulant factor, on the cell surface membrane of monocytes present in PBMC (15). We utilized HD PBMC to address this issue, because we could obtain only two $\mathrm{PB}$ samples from patient RP2 and the patient's response to Zol with respect to $\mathrm{TNF} \alpha$ secretion was similar to that of HD (Figure 2). Thus, $\mathrm{HD}$ PBMC were incubated $\mathrm{ON}$ in medium alone or medium containing Zol. Subsequently, LPS, a known inducer of TF-1 on monocytes, was added to the medium for an additional $3 \mathrm{~h}$. The expression of the CD142 antigen, which identifies TF-1 on the cell surface, was assessed by FACS analysis after gating on CD14+ monocytes. A marked and significant upregulation of CD142 on HD-derived monocytic CD14+ cells cultured with either Zol alone ON or after the brief $3 \mathrm{~h}$ LPS stimulation was observed (Figure 3). There was no upregulation of CD14 in these experiments, indicating that upregulation of CD142 was not due to non-specific elevation of surface membrane molecules on monocytes (data not shown). Furthermore, an additive effect on CD142 levels of expression was noted in PBMC cultured in the presence of both reagents (Figure 3).

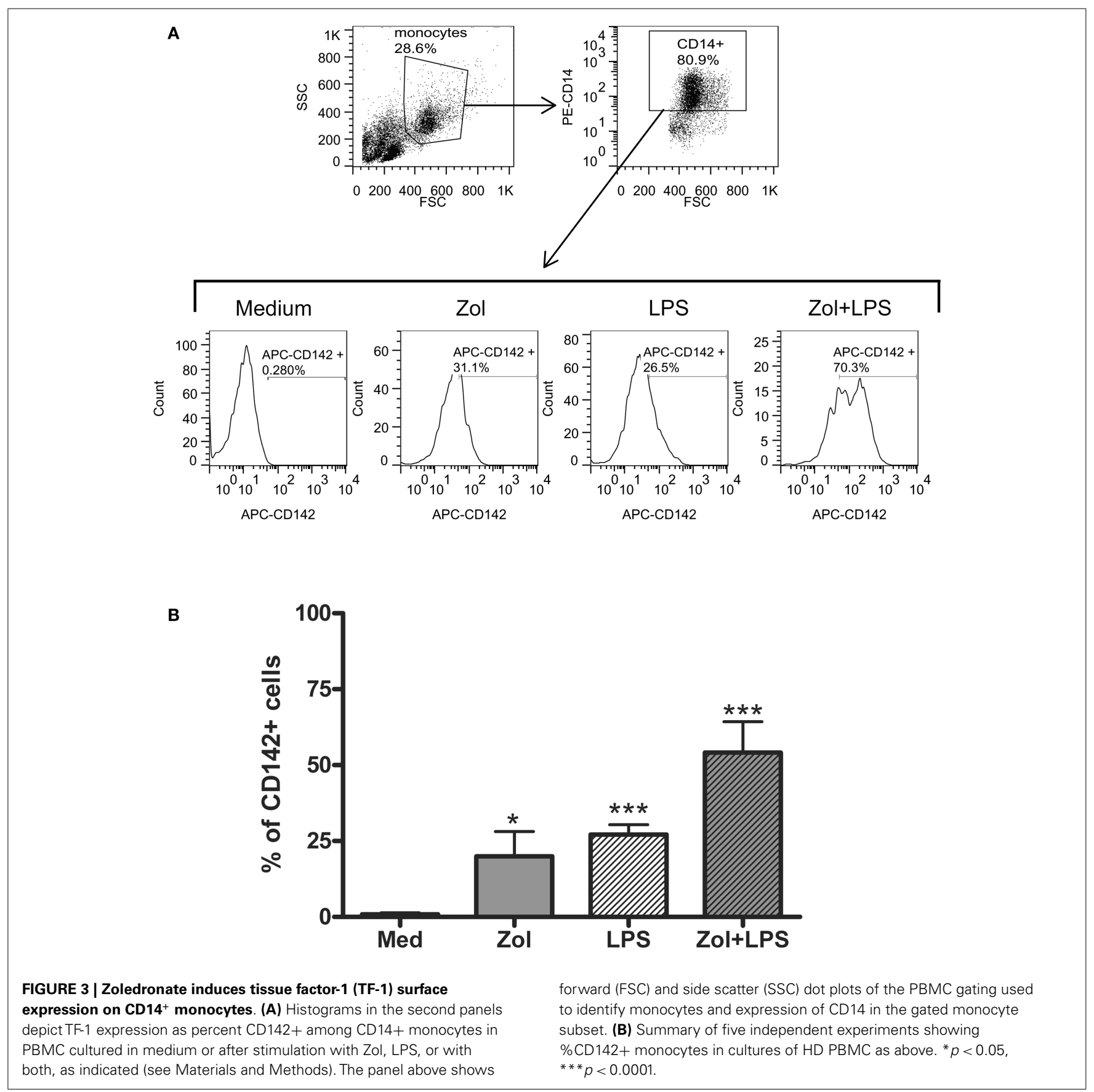


We next performed similar experiments and included infliximab, a TNF $\alpha$ neutralizing humanized $\mathrm{mAb}$, or similar concentrations of non-specific human IgG, in parallel cultures. Infliximab abolished, in a dose-dependent manner, induction of TF-1 on the surface membrane of CD14+ monocytes in response to Zol but not to LPS (Figure 4). Although control IgG also slightly reduced TF-1 expression induced by Zol, inhibition was incomplete even at high concentrations of IgG. Together, these results indicate that Zol, when added to PBMC, induces TNF $\alpha$ secretion by the $\mathrm{V} \gamma 9 \delta 2+$ $\mathrm{T}$ cells in the PBMC and TNF $\alpha$-dependent expression of TF-1 on CD14+ monocytes.

\section{EFFECT OF PATIENT PLASMA ON TF-1 INDUCTION}

Zoledronate has not been previously reported to induce digital necrosis despite its widespread use in patients. Furthermore, in our experience, which included four SSc patients, only RP2 developed an APR and critical digital ischemia, in which TF-1 may have contributed. It was thus of interest to determine the role of RP2 patient specific factors in the development of the unusual response to Zol. We found that addition of RP2-plasma (RP2-P) markedly increased TF-1 induction on CD14+ monocytes in response to Zol as well as LPS, whereas control plasma (RP1-P) from SSc patient RP1 who had received Zol with no toxic effect did not enhance TF-1 induction (Figure 5). Importantly, addition of anti-TNF $\alpha$ $\mathrm{mAb}$ but not of non-specific IgG still completely abolished TF-1 upregulation in response to Zol even in the presence of RP2-P. Anti-TNF $\alpha \mathrm{mAb}$ did not reduce TF-1 upregulation in response to LPS or the combination of LPS and Zol in the presence of RP2-P. These results suggest that the patient's plasma specifically contained factor/s that enhance Zol-induced $\mathrm{V} \gamma 9 \delta 2+$ produced $\mathrm{TNF} \alpha$-dependent TF-1 expression on monocytes in vitro, suggesting that a similar effect may have taken place following IV infusion on her circulating monocytes.

\section{DISCUSSION}

This paper shows, for the first time, an SSc specific effect of Zol, i.e., the enhancement of IL- 4 secretion by $\mathrm{PB} V \delta 1+\mathrm{T}$ cells, coupled with diminished ability of these cells to secrete IL-9 relative to two patients with another form of fibrosing disease, IPF. Furthermore, Zol induced secretion of TNF $\alpha$ by $\mathrm{V} \gamma 9 \delta 2+\mathrm{T}$ cells from some SSc patients similar to healthy individuals, which in turn induced TF1 on CD14+ monocytes. Finally, plasma of an SSc patient who suffered a clinically detrimental inflammatory response strongly augmented this TNF $\alpha$-dependent TF- 1 expression on monocytes. These data suggest that activation of both major $\gamma \delta$ T cell subsets $\mathrm{V} \delta 1+$ and $\mathrm{V} \gamma 9 \delta 2+$ by Zol could activate pathogenic mechanisms, e.g., fibrosis (via IL-4) and thrombosis (via TF-1) - relevant to clinical manifestations in SSc patients.

The bisphosphonate-induced APR in patients receiving intravenous therapy for osteoporosis or cancer differs from a typical APR. Thus, CD14+ monocytes and macrophages are the primary cytokine producing cells in the latter, whereas bisphosphonates induce rapid and copious production of TNF $\alpha$, IFN $\gamma$, and IL-6 primarily by $\mathrm{PB} V \gamma 9 \delta 2 \mathrm{~T}$ cells (16). Activation of the $\mathrm{V} \gamma 9 \delta 2+$ $\mathrm{T}$ cells triggered by upregulation of IPP in monocytes in turn enhances CD14, CD40, CD80, and HLA-DR on circulating monocytes (8). Zol also enhances TNF-related apoptosis-inducing ligand (TRAIL) in $\gamma \delta \mathrm{T}$ and NK cells, and release of high mobility group box 1 (HMGB1) from $\gamma \delta$ T cells and monocytes (17). Furthermore, soluble factors released by activated $\mathrm{V} \delta 2 /$ monocytes cocultures induce granulocyte migration and activation (18). Activated $\mathrm{V} \gamma 9 \delta 2 \mathrm{~T}$ cells also trigger granulocyte functions via MCP-2 release during bacterial infection (9).

The novel finding shown here, i.e., induction of TF-1 on monocytes, in a manner dependent upon $\mathrm{TNF} \alpha$ produced by $\mathrm{V} \gamma 9 \delta 2+$ $\mathrm{T}$ cells stimulated with Zol, adds an additional dimension to the role of monocyte- $\mathrm{V} \gamma 9 \delta 2$ interactions, that may play a critical role in clinical medicine, since TF-1 expressing monocytes play an important role in thrombotic diseases (19). For example, patients with cardio- and cerebro-vascular disease have increased TF-1 expression on circulating monocytes and TF-1-positive monocytederived circulating microparticles in the blood (20, 21). Furthermore, circulating monocyte-derived microparticles expressing TF-1 are associated with acute recurrent deep venous thrombosis (22). In experimental hypercholesterolemic mice, the associated prothrombotic state is caused by oxidized low density lipoprotein

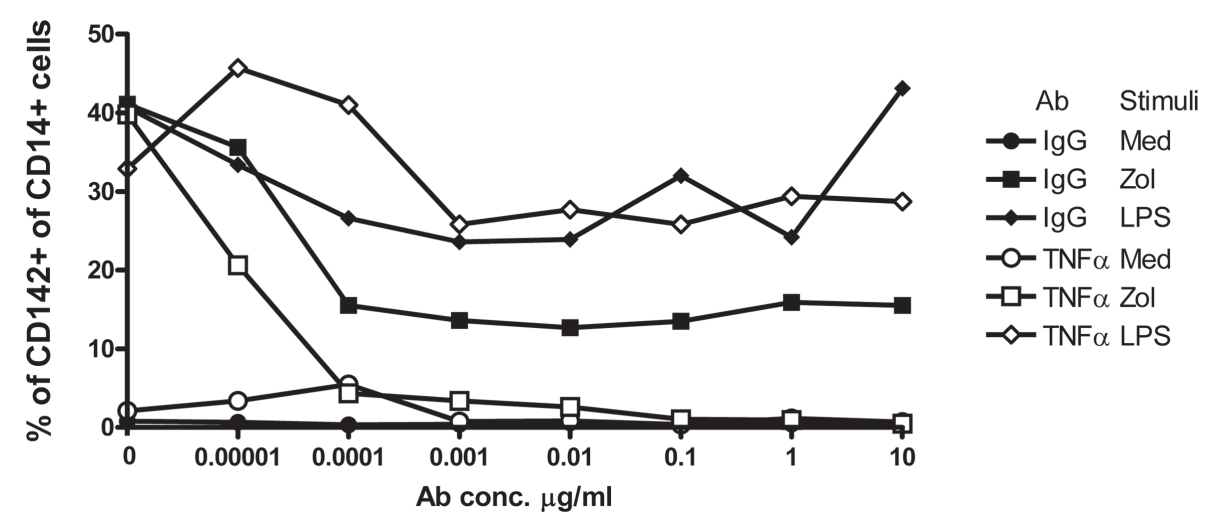

FIGURE 4 | Upregulation of TF-1 in response to Zol is TNF $\alpha$-dependent. PBMC from a healthy donor were cultured in medium with graded dilutions (indicated on the $x$ axis) of either anti-TNF $\alpha$ mAb or control IgG. Cells were stimulated with Zol, with LPS or not stimulated (medium), and TF-1 was measured by flow cytometry as described in Figure 3. Results are representative of three experiments 

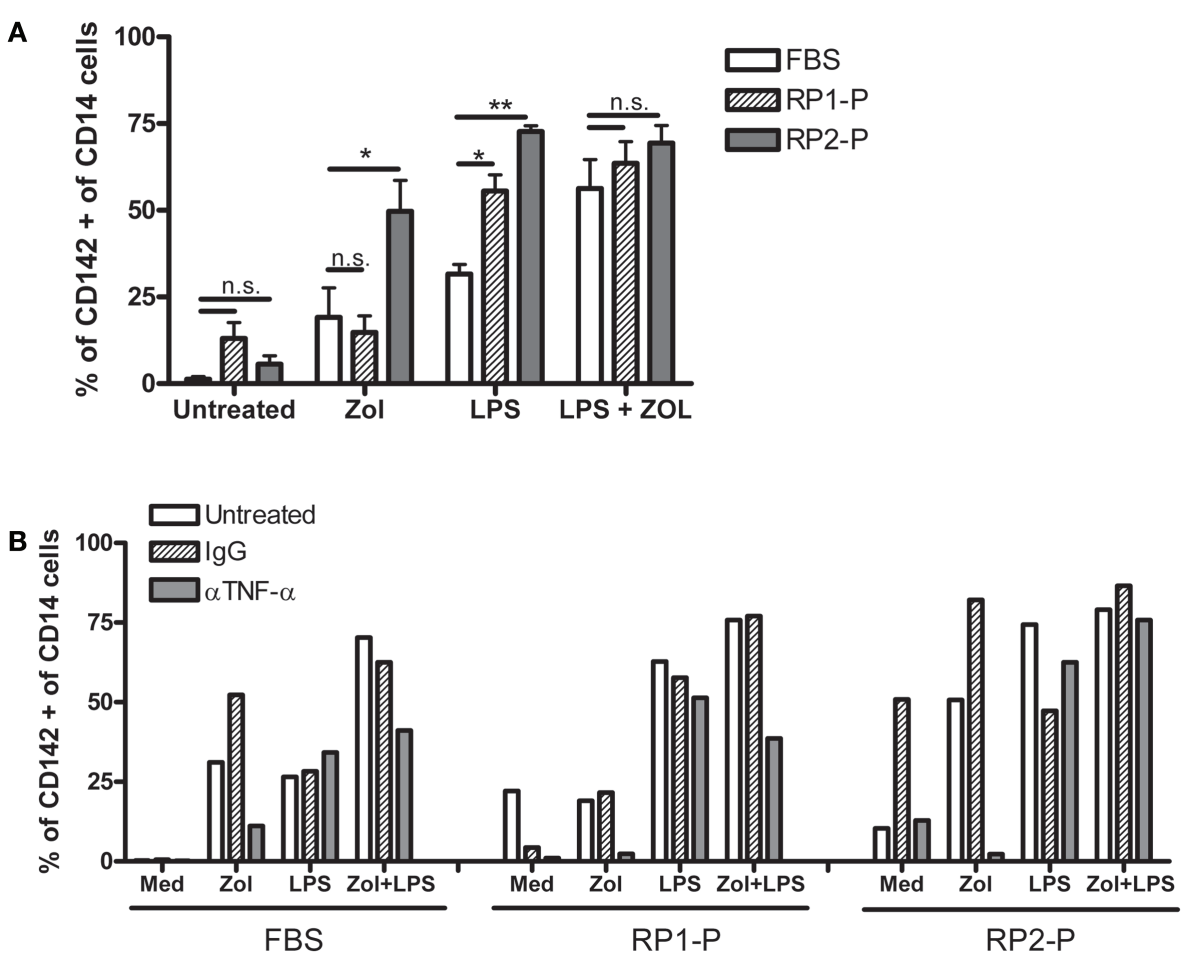

FIGURE 5 | RP2-plasma increases TNF $\alpha$-dependent upregulation of TF-1 in response to LPS and Zol. (A) Bars represent percent \pm 1 SEM of CD14+ cells expressing TF-1 (CD142) in PBMC cultures from three HDs, cultured with the indicated stimuli on the $X$ axis, in the presence of medium containing 10\% FBS or RP1- or RP2-plasma (RP1-P or RP2-P). (B) Shows the same experiment done in the presence of $10 \mu \mathrm{g} / \mathrm{ml}$ anti-TNF $\alpha$ antibody or control lgG as indicated. engagement of a toll-like receptor (TLR)4/TLR6 complex, leading to induction of TF-1 in monocytes (23). In addition, in rats, monocytes in blood vessels of kidneys undergoing acute rejection express high levels of TF-1 (24). These data suggest that Zol infusion, which achieves concentrations of zoledronate in the plasma similar to those we have used in our experiments, may lead to induction of TF-1 on circulating monocytes resulting in a prothrombotic state, which may have contributed to development of ischemic digits in SSc RP2 patient described here (25). Our data, furthermore, show that Zol-induced TF-1 on monocytes is at least partly dependent upon $\mathrm{V} \gamma 9 \delta 2$ cell produced $\mathrm{TNF} \alpha$ (Figures 1 and 5). In contrast, a combination of mAb to TNF $\alpha$ and IL-1 $\beta$, but neither alone, was required to inhibit high molecular weight kininogen induced monocyte TF-1 (26). TNF $\alpha$ may also upregulate monocyte TF-1 activity indirectly via its effects on endothelial cells $(27,28)$.

Although Zol induced increase of TF-1 on monocytes, overt thrombosis in the absence of additional factors is rare. Nevertheless, inclusion of zoledronic acid in the treatment protocols for multiple myeloma (MM) and breast cancer significantly increases venous thrombosis (29-32). In this regard, $\mathrm{V} \gamma 9 \delta 2+\mathrm{T}$ cells may be playing a role, since in both $\mathrm{MM}$ and breast cancer patients, these cells are known to become activated by Zol (33-36). These data suggest that Zol-induced thrombosis is dependent upon disease and/or patient specific factors, which may include Zol responsive $\mathrm{V} \gamma 9 \delta 2+\mathrm{T}$ cells in the PB and additional factors.
Our data suggest that SSc may constitute a risk for severe prothrombotic $\gamma \delta \mathrm{T}$ cell-mediated Zol-induced reactions. In this regard, the already diseased endothelium in SSc may play a role, since activated $\gamma \delta$ T cells of SSc patients, in particular, adhere to and damage endothelial cells, creating a substrate for enhancing thrombosis (37). The current data suggest that at least two additional factors could play a role in Zol-induced thrombosis in SSc patients. First, SSc patient's plasma may contain factors that enhance TF-1 expression in response to Zol [Figure 5 and Ref. (16)]. Indeed, SSc plasma has been shown previously to contain increased levels of circulating TNF $\alpha$, platelet microparticles, and soluble CD40 ligand, which could collaborate in the induction of TF-1 (38). That TF-1 induction in the setting of exposure to Zol can be blocked by an anti-TNF $\alpha$ antibody even in the presence of enhancement by patient's plasma (Figure 5) suggests that $\mathrm{TNF} \alpha$ released by Zol-activated $\mathrm{V} \gamma 9 \delta 2+\mathrm{T}$ cells plays a major role in induction of TF-1 and that anti-TNF $\alpha \mathrm{mAb}$ could be used to prevent thrombosis in high risk SSc patients treated with Zol. In addition, our study is the first, to our knowledge, to describe a disease-specific IL-4 response of SSc patients $\mathrm{V} \delta 1+\mathrm{T}$ cells to Zol (Figure 1). A bias toward IL-4 secretion by SSc patients CD4+ TCR $\alpha \beta$ T cells in response to non-specific stimulation has already been observed (39). Moreover, $\mathrm{V} \delta 1+$ $\gamma \delta \mathrm{T}$ cells often predominate in the context of a Th2-biased environment, e.g., in the broncho-alveolar lavage fluid obtained from allergic individuals $(40,41)$. In addition, the majority of 
phosphatidyl-ethanolamine CD1d-restricted $\gamma \delta \mathrm{T}$ clones in allergic individuals are V $\delta 1+$ and secrete high levels of IL-4 (42). We hypothesize that Zol stimulation may upregulate co-stimulatory monocytes CD40, CD80, and CD1d molecules, which in turn, enhance IL-4 secretion by CD1d-restricted lipid antigen responsive V $81+\mathrm{T}$ cells in the PB of SSc patients $(43,44)$. The combined effects of the TNF $\alpha$ secreted by $V \gamma 9 \delta 2$ cells, together with the IL- 4 produced by $\mathrm{V} \delta 1+\mathrm{T}$ cells increases vascular cell adhesion molecule 1 (VCAM-1) expression on endothelial cells in digital arteries and VCAM-1-mediated adhesion of TF-1+ monocytes to the endothelium could then activate local thrombosis and gangrene (45).

In summary, the hitherto described disastrous consequences of a seemingly innocuous and highly utilized drug, Zol, in an SSc patient, which prompted these investigations, led to the discovery of a novel prothrombotic pathway involving $\mathrm{V} \gamma 9 \delta 2 \gamma \delta \mathrm{T}$ cells and CD14+ monocytes and a disease-specific activation of IL-4 producing $V \delta 1 \gamma \delta \mathrm{T}$ cells. Future studies into this pathway may lead to new insights into the immunopathogenic mechanisms of thrombotic diathesis in immune-mediated, infectious, and malignant diseases, in which $\gamma \delta \mathrm{T}$ cells play a role.

\section{ACKNOWLEDGMENTS}

Supported by the Gerald Baum grant from the Israel Lung Association to Ilan Bank.

\section{REFERENCES}

1. Hayday AC. [gamma][delta] cells: a right time and a right place for a conserved third way of protection. Annu Rev Immunol (2000) 18:975-1026. doi:10.1146/annurev.immunol.18.1.975

2. Caccamo N, Dieli F, Wesch D, Jomaa H, Eberl M. Sex-specific phenotypical and functional differences in peripheral human Vgamma9/Vdelta2 T cells. J Leukoc Biol (2006) 79:663-6. doi:10.1189/jlb.1105640

3. Vavassori S, Kumar A, Wan GS, Ramanjaneyulu GS, Cavallari M, El Daker S, et al. Butyrophilin 3A1 binds phosphorylated antigens and stimulates human gammadelta T cells. Nat Immunol (2013) 14:908-16. doi:10.1038/ni.2665

4. Bai L, Picard D, Anderson B, Chaudhary V, Luoma A, Jabri B, et al. The majority of CD1d-sulfatide-specific T cells in human blood use a semi invariant Vdeltal TCR. Eur J Immunol (2012) 42:2505-10. doi:10.1002/eji.201242531

5. Ueda-Hayakawa I, Hasegawa M, Hamaguchi Y, Takehara K, Fujimoto M. Circulating gamma/delta T cells in systemic sclerosis exhibit activated phenotype and enhance gene expression of proalpha2(I) collagen of fibroblasts. J Dermatol Sci (2013) 69:54-60. doi:10.1016/j.jdermsci.2012.10.003

6. Bendersky A, Markovits N, Bank I. Vgamma9+ gammadelta T cells in systemic sclerosis patients are numerically and functionally preserved and induce fibroblast apoptosis. Immunobiology (2010) 215:380-94. doi:10.1016/j.imbio. 2009.05.012

7. Kabelitz D, Glatzel A, Wesch D. Antigen recognition by human gammadelta T lymphocytes. Int Arch Allergy Immunol (2000) 122:1-7. doi:10.1159/ 000024353

8. Welton JL, Morgan MP, Marti S, Stone MD, Moser B, Sewell AK, et al. Monocytes and gammadelta $\mathrm{T}$ cells control the acute-phase response to intravenous zoledronate: insights from a phase IV safety trial. J Bone Miner Res (2013) 28(3):464-71. doi:10.1002/jbmr.1797

9. Eberl M, Roberts GW, Meuter S, Williams JD, Topley N, Moser B. A rapid crosstalk of human gammadelta $\mathrm{T}$ cells and monocytes drives the acute inflammation in bacterial infections. PLoS Pathog (2009) 5:e1000308. doi:10.1371/ journal.ppat.1000308

10. Sarhan D, D’Arcy P, Wennerberg E, Liden M, Hu J, Winqvist O, et al. Activated monocytes augment TRAIL-mediated cytotoxicity by human NK cells through release of IFN-gamma. Eur J Immunol (2013) 43:249-57. doi:10.1002/ eji.201242735

11. Conti L, Casetti R, Cardone M, Varano B, Martino A, Belardelli F, et al. Reciprocal activating interaction between dendritic cells and pamidronate-stimulated gammadelta T cells: role of CD86 and inflammatory cytokines. JImmunol (2005) 1(174):252-60. doi:10.4049/jimmunol.174.1.252

12. Tonti E, Jimenez de Oya N, Galliverti G, Moseman EA, Di Lucia P, Amabile A, et al. Bisphosphonates target B cells to enhance humoral immune responses. Cell Rep (2013) 5(2):323-30. doi:10.1016/j.celrep.2013.09.004

13. Subcommittee for scleroderma criteria of the American Rheumatism Association Diagnostic and Therapeutic Criteria Committee. Preliminary criteria for the classification of systemic sclerosis (scleroderma). Arthritis Rheum (1980) 23:581-90. doi:10.1002/art.1780230510

14. Bendersky A, Marcu-Malina V, Berkun Y, Gerstein M, Nagar M, Goldstein I, et al. Cellular interactions of synovial fluid gammadelta $\mathrm{T}$ cells in juvenile idiopathic arthritis. J Immunol (2012) 1(188):4349-59. doi:10.4049/jimmunol.1102403

15. Schwager I, Jungi TW. Effect of human recombinant cytokines on the induction of macrophage procoagulant activity. Blood (1994) 1(83):152-60.

16. Hewitt RE, Lissina A, Green AE, Slay ES, Price DA, Sewell AK. The bisphosphonate acute phase response: rapid and copious production of proinflammatory cytokines by peripheral blood gd $\mathrm{T}$ cells in response to aminobisphosphonates is inhibited by statins. Clin Exp Immunol (2005) 139:101-11. doi:10.1111/j.1365-2249.2005.02665.x

17. Kalyan S, Chow AW. Linking innate and adaptive immunity: human Vgamma9Vdelta2 T cells enhance CD40 expression and HMGB-1 secretion. Mediators Inflamm (2009) 2009:819408. doi:10.1155/2009/819408

18. Davey MS, Lin CY, Roberts GW, Heuston S, Brown AC, Chess JA, et al. Human neutrophil clearance of bacterial pathogens triggers anti-microbial gammadelta T cell responses in early infection. PLoS Pathog (2011) 7:e1002040. doi:10.1371/journal.ppat.1002040

19. Shantsila E, Lip GY. The role of monocytes in thrombotic disorders. Insights from tissue factor, monocyte-platelet aggregates and novel mechanisms. Thromb Haemost (2009) 102:916-24. doi:10.1160/TH09-01-0023

20. Owens AP III, Mackman N. Role of tissue factor in atherothrombosis. Curr Atheroscler Rep (2012) 14:394-401. doi:10.1007/s11883-012-0269-5

21. Oberheiden T, Blahak C, Nguyen XD, Fatar M, Elmas E, Morper N, et al. Activation of platelets and cellular coagulation in cerebral small-vessel disease. Blood Coagul Fibrinolysis (2010) 21:729-35. doi:10.1097/MBC.0b013e328340147c

22. Ye R, Ye C, Huang Y, Liu L, Wang S. Circulating tissue factor positive microparticles in patients with acute recurrent deep venous thrombosis. Thromb Res (2012) 130:253-8. doi:10.1016/j.thromres.2011.10.014

23. Owens AP III, Passam FH, Antoniak S, Marshall SM, McDaniel AL, Rudel L, et al. Monocyte tissue factor-dependent activation of coagulation in hypercholesterolemic mice and monkeys is inhibited by simvastatin. J Clin Invest (2012) 1(122):558-68. doi:10.1172/JCI58969

24. Zakrzewicz A, Wilhelm J, Blocher S, Wilczynska J, Wilker S, Dietrich H, et al. Leukocyte accumulation in graft blood vessels during self-limiting acute rejection of rat kidneys. Immunobiology (2011) 216:613-24. doi:10.1016/j.imbio. 2010.09.009

25. Skerjanec A, Berenson J, Hsu C, Major P, Miller WH Jr, Ravera C, et al. The pharmacokinetics and pharmacodynamics of zoledronic acid in cancer patients with varying degrees of renal function. J Clin Pharmacol (2003) 43:154-62. doi:10.1177/0091270002239824

26. Khan MM, Liu Y, Khan ME, Gilman ML, Khan ST, Bromberg M, et al. Upregulation of tissue factor in monocytes by cleaved high molecular weight kininogen is dependent on TNF-alpha and IL-1beta. Am J Physiol Heart Circ Physiol (2010) 298:H652-8. doi:10.1152/ajpheart.00825.2009

27. Chung J, Koyama T, Ohsawa M, Shibamiya A, Hoshi A, Hirosawa S. 1,25( $\mathrm{OH})(2) \mathrm{D}(3)$ blocks TNF-induced monocytic tissue factor expression by inhibition of transcription factors AP-1 and NF-kappaB. Lab Invest (2007) 87:540-7. doi:10.1038/labinvest.3700550

28. Lo SK, Cheung A, Zheng Q, Silverstein RL. Induction of tissue factor on monocytes by adhesion to endothelial cells. J Immunol (1995) 1(154):4768-77.

29. Esmon CT. Does inflammation contribute to thrombotic events? Haemostasis (2000) 30(Suppl 2):34-40. doi:10.1159/000054161

30. Aft R, Naughton M, Trinkaus K, Watson M, Ylagan L, Chavez-MacGregor M, et al. Effect of zoledronic acid on disseminated tumour cells in women with locally advanced breast cancer: an open label, randomised, phase 2 trial. Lancet Oncol (2010) 11:421-8. doi:10.1016/S1470-2045(10)70054-1

31. Morgan GJ, Davies FE, Gregory WM, Cocks K, Bell SE, Szubert AJ, et al. Firstline treatment with zoledronic acid as compared with clodronic acid in multiple myeloma (MRC Myeloma IX): a randomised controlled trial. Lancet (2010) 11(376):1989-99. doi:10.1016/S0140-6736(10)62051-X 
32. Tanimoto T, Matayoshi T, Yagasaki F, Takeuchi K, Kami M. Safety and efficacy of zoledronic acid in multiple myeloma. Lancet (2011) 25(377):2178. doi:10.1016/S0140-6736(11)60959-8

33. Capietto AH, Martinet L, Fournie JJ. Stimulated gammadelta T cells increase the in vivo efficacy of trastuzumab in HER-2+ breast cancer. J Immunol (2011) 15(187):1031-8. doi:10.4049/jimmunol.1100681

34. Mariani S, Muraro M, Pantaleoni F, Fiore F, Nuschak B, Peola S, et al. Effector gammadelta $\mathrm{T}$ cells and tumor cells as immune targets of zoledronic acid in multiple myeloma. Leukemia (2005) 19:664-70. doi:10.1038/sj.leu. 2403693

35. Meraviglia S, Eberl M, Vermijlen D, Todaro M, Buccheri S, Cicero G, et al. In vivo manipulation of Vgamma9Vdelta2 $\mathrm{T}$ cells with zoledronate and low-dose interleukin-2 for immunotherapy of advanced breast cancer patients. Clin Exp Immunol (2010) 161:290-7. doi:10.1111/j.1365-2249.2010. 04167.x

36. Santini D, Martini F, Fratto ME, Galluzzo S, Vincenzi B, Agrati C, et al. In vivo effects of zoledronic acid on peripheral gammadelta $\mathrm{T}$ lymphocytes in early breast cancer patients. Cancer Immunol Immunother (2009) 58:31-8. doi:10.1007/s00262-008-0521-6

37. Kahaleh MB, Fan PS, Otsuka T. Gammadelta receptor bearing T cells in scleroderma: enhanced interaction with vascular endothelial cells in vitro. Clin Immunol (1999) 91:188-95. doi:10.1006/clim.1999.4694

38. Nomura S, Inami N, Ozaki Y, Kagawa H, Fukuhara S. Significance of microparticles in progressive systemic sclerosis with interstitial pneumonia. Platelets (2008) 19:192-8. doi:10.1080/09537100701882038

39. O'Reilly S, Hugle T, van Laar JM. T cells in systemic sclerosis: a reappraisal. Rheumatology (Oxford) (2012) 51:1540-9. doi:10.1093/rheumatology/ kes090

40. Spinozzi F, Agea E, Bistoni O, Forenza N, Monaco A, Bassotti G, et al. Increased allergen-specific, steroid-sensitive gamma delta $\mathrm{T}$ cells in bronchoalveolar lavage fluid from patients with asthma. Ann Intern Med (1996) 15(124):223-7.

41. Spinozzi F, Agea E, Bistoni O, Forenza N, Monaco A, Falini B, et al. Local expansion of allergen-specific CD30+Th2-type gamma delta T cells in bronchial asthma. Mol Med (1995) 1:821-6.
42. Russano AM, Agea E, Corazzi L, Postle AD, De Libero G, Porcelli S, et al. Recognition of pollen-derived phosphatidyl-ethanolamine by human CD1drestricted gamma delta T cells. J Allergy Clin Immunol (2006) 117:1178-84. doi:10.1016/j.jaci.2006.01.001

43. Ancuta P, Liu KY, Misra V, Wacleche VS, Gosselin A, Zhou X, et al. Transcriptional profiling reveals developmental relationship and distinct biological functions of CD16+ and CD16- monocyte subsets. BMC Genomics (2009) 10:403. doi:10.1186/1471-2164-10-403

44. Skold M, Xiong X, Illarionov PA, Besra GS, Behar SM. Interplay of cytokines and microbial signals in regulation of CD1d expression and NKT cell activation. J Immunol (2005) 15(175):3584-93. doi:10.4049/jimmunol.175.6.3584

45. Iademarco MF, Barks JL, Dean DC. Regulation of vascular cell adhesion molecule-1 expression by IL-4 and TNF-alpha in cultured endothelial cells. J Clin Invest (1995) 95:264-71. doi:10.1172/JCI117650

Conflict of Interest Statement: The authors declare that the research was conducted in the absence of any commercial or financial relationships that could be construed as a potential conflict of interest.

Received: 14 July 2014; paper pending published: 04 August 2014; accepted: 15 August 2014; published online: 08 September 2014.

Citation: Marcu-Malina V, Balbir-Gurman A, Dardik R, Braun-Moscovici Y, Segel $M J$ and Bank I (2014) A novel prothrombotic pathway in systemic sclerosis patients: possible role of bisphosphonate-activated $\gamma \delta T$ cells. Front. Immunol. 5:414. doi: 10.3389/fimmu.2014.00414

This article was submitted to T Cell Biology, a section of the journal Frontiers in Immunology.

Copyright (C) 2014 Marcu-Malina, Balbir-Gurman, Dardik, Braun-Moscovici, Segel and Bank. This is an open-access article distributed under the terms of the Creative Commons Attribution License (CC BY). The use, distribution or reproduction in other forums is permitted, provided the original author(s) or licensor are credited and that the original publication in this journal is cited, in accordance with accepted academic practice. No use, distribution or reproduction is permitted which does not comply with these terms. 